TEMAS EMERGENTES

\title{
Las personas con discapacidad en el proceso electoral de convencionales constituyentes en Chile: Las lecciones aprendidas
}

\author{
Persons with disabilities in the electoral process of conventional \\ constituents in Chile: Lessons learned
}

\author{
María Soledad Cisternas Reyes \\ Enviada Especial del Secretario General sobre Discapacidad \\ y Accesibilidad de Naciones Unidas
}

\begin{abstract}
RESUMEN La presente monografía explica el rol de las personas con discapacidad en el proceso electoral de convencionales constituyentes en Chile en 2021. Se presentan las principales argumentaciones de la sociedad civil de personas con discapacidad para lograr la adopción de la modificación constitucional que estableció cupos del 5\% como mínimo para personas con discapacidad en las listas de partidos políticos y en las listas electorales de pactos de partidos políticos. Además, nos proponemos que los lectores y las lectoras conozcan el resultado en la aplicación de estos cupos en las listas, con lo cual se llega a las lecciones aprendidas para el futuro electoral chileno en cuanto a dos temas: contemplar de manera permanente para elecciones al Congreso Nacional los cupos para personas con discapacidad en las listas de partidos y pactos electorales de partidos; y que en la aplicación del sistema de paridad de género se apliquen medidas de acción afirmativa para lograr una paridad justa sin exclusiones que impliquen retroceder en los derechos políticos de un sector tradicionalmente infra protegido.
\end{abstract}

PALABRAS CLAVE Derechos humanos, Convención Constitucional, cupos reservados, medidas de acción afirmativa, paridad de género.

ABSTRACT This monograph explains the role of persons with disabilities in the electoral process for the election of Constituent Assembly members in Chile in 2021. It presents the main arguments of the civil society of persons with disabilities to achieve the adoption of the constitutional amendment that established quotas of at least $5 \%$ for persons with disabilities in the lists of political parties and in the electoral lists of political party pacts. In addition, we propose that readers learn the results of the application of these quotas in the lists, which will lead to the lessons learned for the future of Chilean 
elections regarding two issues: to contemplate permanently for elections to the National Congress the quotas for persons with disabilities in the lists of parties and electoral pacts of parties; and that in the application of the gender parity system, affirmative action measures are applied to achieve a fair parity without exclusions that imply a setback in the political rights of a traditionally under protected sector.

KEYWORDS Human rights, Constitutional Convention, reserved quotas, affirmative action measures, gender parity.

\section{Proyecto de reforma constitucional}

El proyecto de ley que trataba sobre la «Carta Fundamental, para reservar escaños a representantes de los pueblos originarios en la integración del órgano constituyente que se conforme para la creación de una nueva constitución política de la República» (Boletín 13.129-07) contenía en su parte final una reforma para facilitar la participación de las personas con discapacidad en la elección de convencionales constituyentes de 2021. En esta se establecía un cupo mínimo del 10\% de candidatos y candidatas con discapacidad en las respectivas listas. ${ }^{1}$

Durante la tramitación en el Senado hubo una mirada predominante en cuanto a eliminar los incisos referidos a discapacidad por no decir relación con la idea matriz del proyecto, que se refería a escaños reservados para pueblos indígenas. Como máximo, para mantener el propósito de estos cupos reservados para personas con discapacidad, había una indicación para que el cupo fuese del 1\% de estos candidatos en las listas. ${ }^{2}$

Esta noticia causó gran conmoción en los sectores de personas con discapacidad, lo que llevó a que, estando próxima a votarse en la Comisión de Constitución, Legislación y Justicia del Senado la medida de eliminación o, en el mejor de los casos, la reducción al $1 \%$ de la reserva, el Colectivo Nacional de la Discapacidad (Conadis) enviara una carta a la Comisión y encomendara a una integrante del colectivo, persona con discapacidad, que hiciese una defensa de la mencionada modificación constitucional para hacer valer los argumentos que justificaban los cupos reservados. ${ }^{3} \mathrm{La}$ Comisión otorgó una audiencia para estos efectos, pero en la práctica, después de

1. Boletín 13.129-07, 2020, «Modifica Carta Fundamental, para reservar escaños a representantes de los pueblos originarios en la integración del órgano constituyente que se conforme para la creación de una nueva Constitución Política de la República».

2. «Indicación de los honorables senadores señora Aravena y señores Galilea y Prohens», Biblioteca del Congreso Nacional, 13 de agosto de 2020, disponible en https://bit.ly/31vLXfz.

3. «Comisión de Constitución, Legislación, Justicia y Reglamento», Televisión del Senado, 26 de octubre de 2020, disponible en https://bit.ly/31BsREA. 
muchas presentaciones anteriores para escaños a pueblos originarios, la presentación en discapacidad contó con pocos minutos. La representante del sector de la discapacidad hizo notar que el tema requería ser abordado en profundidad y no podría ser restringido a un mínimo tiempo. Por esta razón, la audiencia se extendió y se continuó al día siguiente. ${ }^{4}$

¿Cuáles fueron los argumentos esgrimidos ante la Comisión del Senado que permitieron revivir el proyecto de modificación constitucional para cupos en las listas para convencionales constituyentes con discapacidad? Se comenzó haciendo presente los compromisos asumidos por Chile a nivel internacional y otros estándares internacionales. En efecto, la Convención sobre los Derechos de las Personas con Discapacidad de Naciones Unidas (CDPD), ratificada por Chile en el año 2008, reconoce el modelo social de las personas con discapacidad, conceptualizando como titular de derechos a quienes presentan «deficiencias físicas, mentales, intelectuales o sensoriales a largo plazo que, al interactuar con diversas barreras, puedan impedir su participación plena y efectiva en la sociedad, en igualdad de condiciones con las demás».5

En este nuevo paradigma, que deja atrás los enfoques de beneficencia y médicoasistencialistas, un factor crucial para determinar la discapacidad es la interacción con barreras que experimenta una persona que presenta deficiencias. Precisamente, la medición de esta interacción se centrará en las restricciones a la participación plena y efectiva de dichas personas en la sociedad.

En consecuencia, la obligación principal de eliminar barreras es del Estado, al mismo tiempo de crear condiciones para la igualación de oportunidades. En esta línea, la CDPD se ocupó expresamente de prescribir el derecho de las personas con discapacidad a la participación política y pública, lo que implica su derecho a presentarse efectivamente como candidatas en las elecciones, ejercer cargos y desempeñar cualquier función pública a todos los niveles de gobierno.

De este modo, los Estados partes deberán garantizar a las personas con discapacidad los derechos políticos y la posibilidad de gozar de ellos en igualdad de condiciones con las demás, lo que incluye también promover activamente un entorno en el que las personas con discapacidad puedan participar plena y efectivamente en la dirección de los asuntos públicos, sin discriminación y en igualdad de condiciones con las demás.

Lo anterior está en línea con la prescripción de la Convención en cuanto a las obligaciones generales de los Estados, una de las cuales es efectuar consultas estrechas,

4. «Comisión de Constitución, Legislación, Justicia y Reglamento», Televisión del Senado, 27 de octubre de 2020, disponible en https://bit.ly/3Gvpu13.

5. Convención sobre los Derechos de las Personas con Discapacidad, Asamblea General de Naciones Unidas, 13 de diciembre de 2006, disponible en https://bit.ly/3pD9W4j. 
colaborando activamente con las personas con discapacidad, incluidos los niños y las niñas con discapacidad, a través de las organizaciones que las representan (artículo 4, número 3).

La Observación General 7 del Comité sobre los Derechos de las Personas con Discapacidad de Naciones Unidas ha señalado que «los Estados partes deberían considerar las consultas y la integración de las personas con discapacidad como medida obligatoria antes de aprobar leyes, reglamentos y políticas, ya sean de carácter general o relativos a la discapacidad». ${ }^{6}$ Es decir, de acuerdo a los compromisos asumidos por el Estado chileno al ratificar la Convención, la participación de personas con discapacidad en los procesos de toma de decisiones, incluidos aquellos tan importantes como la redacción de una nueva constitución, no es una invitación, sino una obligación.

Por su parte, el Consejo de Derechos Humanos de Naciones Unidas, en el «Estudio temático sobre la participación de las personas con discapacidad en la vida política y pública», 7 enfatizó que no hay duda sobre el derecho de las personas con discapacidad a participar en todos los aspectos de la vida política y pública de su país, el que no es solo un objetivo en sí mismo, sino también un requisito para el disfrute efectivo de los demás derechos. Al participar en la reforma de las leyes y políticas que les afectan, las personas con discapacidad y las organizaciones que las representan pueden lograr cambios en la sociedad y mejorar la legislación y las políticas en cuanto a la salud, la rehabilitación, la educación, el empleo, el acceso a bienes y servicios, y cualquier otro aspecto de la vida (Observación General 7, párrafo 18).

Se ha observado, sin embargo, que las políticas diseñadas a la fecha no han resultado efectivas para alcanzar la igualdad material o real de este colectivo históricamente marginado, debido a los altos grados de vulneración que viven las personas con discapacidad. Es por esta razón que se han implementado medidas de acción afirmativa en algunos ámbitos, con el objeto de acelerar los procesos de inclusión social y alcanzar una igualdad de hecho o de resultados. Se busca un equilibrio en los bienes y en las condiciones sociales y económicas, lo cual implica, en ocasiones, una redistribución en favor de sectores históricamente infraprotegidos.

El tratamiento normativo de las medidas de acción afirmativa en la CDPD expresa que no se considerarán discriminatorias las medidas específicas que sean necesarias para acelerar o lograr la igualdad de hecho de las personas con discapacidad (artículo

6. Comité sobre los Derechos de las Personas con Discapacidad de Naciones Unidas. Observación General 7, «Sobre la participación de las personas con discapacidad, incluidos los niños y las niñas con discapacidad, a través de las organizaciones que las representan, en la aplicación y el seguimiento de la Convención», párr. 15, disponible en https://bit.ly/31xbaGv.

7. «Estudio temático preparado por la Oficina del Alto Comisionado de las Naciones Unidas para los Derechos Humanos sobre la participación de las personas con discapacidad en la vida política y pública», Asamblea General de Naciones Unidas, A/HRC/19/36, 21 de diciembre de 2011, disponible en https://bit.ly/3rNapDS. 
5, inciso cuarto). Además, el Consejo de Derechos Humanos de Naciones Unidas ha subrayado que los Estados gozan de cierto margen de apreciación a la hora de determinar las medidas que deben adoptarse para garantizar que las personas con discapacidad puedan efectivamente participar en la dirección de los asuntos públicos de su país en condiciones de igualdad con las demás. Sin embargo, cuando esto no sucede, la mera pasividad por parte del Estado constituye una violación de ese derecho.

Desde un enfoque de derechos humanos, la igualdad ha sido interpretada en el sentido de que todas las personas son iguales y que, a pesar de nuestras diferencias, todos y todas poseemos un valor inherente y tenemos los mismos derechos humanos por el simple hecho de existir; la diversidad no obsta a la igualdad.

Cuando el principio de igualdad es puesto en práctica, se requiere que cada individuo y la sociedad en las cuales viven las personas valoren y acomoden cualquier diferencia humana, incluyendo aquellas basadas en la discapacidad. Es así como en el enfoque de «igualdad efectiva, material o sustantiva» se busca garantizar la igualdad de resultados y no solo la igualdad de oportunidades. El solo indicar que las personas son iguales no suele ser suficiente para que así sea.

Ejemplo de este enfoque constituiría la creación de leyes destinadas directamente al colectivo de personas con discapacidad, con el objeto de aumentar su número en el mundo laboral o su participación política. El principio de no discriminación se encuentra incorporado en todos los tratados de derechos humanos del sistema multilateral, incluida la CDPD, que define como discriminación por motivos de discapacidad a

cualquier distinción, exclusión o restricción por motivos de discapacidad que tenga el propósito o el efecto de obstaculizar o dejar sin efecto el reconocimiento, goce o ejercicio, en igualdad de condiciones, de todos los derechos humanos y libertades fundamentales en los ámbitos político, económico, social, cultural, civil o de otro tipo. Incluye todas las formas de discriminación, entre ellas, la denegación de ajustes razonables (artículo 2, inciso tercero).

La misma Convención subraya que los Estados partes prohibirán este tipo de discriminación, garantizando a todas las personas con discapacidad protección legal, igual y efectiva contra la discriminación por cualquier motivo, ya que reconoce que todas las personas son iguales ante la ley y tienen derecho a igual protección (artículo 5, inciso primero).

El principio de no discriminación abarca, por lo tanto, el compromiso de no participar en acciones u omisiones discriminatorias y de tomar medidas para contrarrestar formas de discriminación indirectas. Los Estados deben asegurarse de abordar los problemas de discriminación, independientemente si esta se produce solo entre individuos o de una manera más sistémica, como por ejemplo a través de la legislación, las políticas públicas, el funcionamiento y actuación de los entes públicos. 
Los principios de no discriminación e igualdad interactúan entre sí, y colocan a los Estados en una alerta permanente para detectar y adoptar medidas con el objeto de lograr la igualdad de aquellas personas históricamente vulneradas y marginadas, contando con la facultad de concebir y aplicar un trato diferenciado basado en la razonabilidad. Estas acciones se proponen lograr la igualdad material o, de hecho, establecer una situación más equilibrada, en consideración a las desventajas históricas experimentadas por las personas con discapacidad. Estas acciones tratan a las personas de manera efectiva, no se consideran «discriminación» porque el objetivo es superar las desventajas, lograr la igualdad y promover, en lugar de violar el disfrute de los derechos humanos.

Los principios de igualdad y no discriminación no solo interactúan entre sí, sino que también son fundamentalmente indivisibles, interrelacionados e interdependientes con todos los demás derechos humanos. Por ejemplo, en el caso de las personas con discapacidad, no es suficiente decir que este sector no debe ser discriminado para disfrutar el derecho a ser elegidos en cargos de representación popular si no se brindan las herramientas para que puedan participar en elecciones populares. De manera similar, no es suficiente que el Estado brinde estas herramientas si las personas con discapacidad se enfrentan a discriminación cuando las usan.

Por lo mismo, si en esta perspectiva de representación descriptiva existe una preocupación por reflejar en el sistema político la diversidad de la sociedad, entonces resulta esperable que se propicien mecanismos para garantizar que aquello ocurra. Las medidas de acción afirmativa (cuotas especiales, asientos reservados e incentivos específicos) observan la evidencia histórica e intentan subsanarla. En otras palabras, no se trata de una compensación basada en la falta cometida en el pasado, sino de una acción para contribuir a remediar las desigualdades de poder presentes en los sistemas políticos. Se asume que una representación más equilibrada contribuye a distribuir de mejor modo el poder, las decisiones y resultados de política pública.

\section{Agenda 2030 sobre Desarrollo Sostenible}

Por su parte, la Agenda 2030 para el Desarrollo Sostenible de Naciones Unidas, ${ }^{8}$ que se ocupa de las personas, el planeta, la prosperidad y la paz, se basa en derechos humanos y plantea el desafío de «no dejar a nadie atrás». Esto implica la participación efectiva de todas las personas en la sociedad.

En la actualidad existe una interrelación sinérgica entre derechos humanos y el desarrollo sostenible. Por ello, teniendo como soporte jurídico la CDPD de Naciones

8. «La Asamblea General adopta la Agenda 2030 para el Desarrollo Sostenible», Objetivos de Desarrollo Sostenible, 25 de septiembre de 2015, disponible en https://bit.ly/2AyYnTC. 
Unidas, la Agenda 2030 señala expresamente a las personas con discapacidad, haciendo notar la centralidad de la inclusión y de estos titulares de derechos.

Es así como el ODS 10 propone reducir la desigualdad en los países y, entre ellos, hace notar en la meta 10.2 que plantea promover la inclusión política, social y económica, explicitando a las personas con discapacidad. Por su parte, el ODS 16 promueve sociedades pacíficas e inclusivas para el desarrollo sostenible, facilitando el acceso a la justicia para todos, e instituciones eficaces e inclusivas que rindan cuentas. La meta 16.7 propone garantizar la adopción en todos los niveles de decisiones inclusivas, participativas y representativas que respondan a las necesidades de las personas. Es evidente que en esta meta se incluye las decisiones políticas. Aún más, el indicador 16.7.2. se centra en la proporción de la población que considera que la adopción de decisiones es inclusiva y responde a sus necesidades, desglosada por discapacidad, entre otras.

En consecuencia, desde la esfera del desarrollo sostenible, se insta a los Estados a la plena inclusión de las personas con discapacidad en materias políticas, lo que implica también la toma de decisiones y su derecho a presentarse a cargos electivos.

\section{Experiencia comparada}

Es interesante revisar la experiencia comparada en el mundo respecto de la participación política de las personas con discapacidad, tanto en asambleas constituyentes como en congresos y otras entidades públicas cuyos integrantes son electos.

\section{Asambleas constituyentes}

De acuerdo al informe del Programa de Naciones Unidas para el Desarrollo (PNUD), «los miembros que componen la asamblea constituyente actúan como representantes extraordinarios del resto de la nación, por tanto, en este grupo deben estar representados la mayor cantidad de sectores y grupos de la sociedad». ${ }^{9}$ En algunos países se han utilizado mecanismos de acción afirmativa, como cuotas electorales o escaños reservados para asegurar que las asambleas sean inclusivas ${ }^{10} \mathrm{y}$ representativas de toda la sociedad (Bisarya, 2014, 2015).

Hay casos en que se reservan escaños para determinados grupos y son estos los que designan a sus representantes. Por ejemplo, en Colombia, dos escaños fueron reservados para miembros de la guerrilla; en Venezuela, tres para representantes de pueblos indígenas; y en Uganda, 39 escaños para mujeres que fueron elegidas por mujeres integrantes de consejos distritales, más 31 escaños para determinados grupos de interés, entre los que se encuentran las personas con discapacidad.

9. «Mecanismos de cambio constitucional en el mundo», Programa de las Naciones Unidas para el Desarrollo, 19 de octubre de 2015, disponible en https://bit.ly/3DAZgbl.

10. «Mecanismos...», 12. 
El mismo informe da cuenta de los procesos constituyentes a través de asambleas constituyentes en el mundo, correspondiente a 25 casos. Del análisis de estos datos, podemos decir que dichas asambleas constituyentes se celebraron antes de la aprobación de la CDPD en 2006. De haber sido ratificada la Convención por los Estados a la fecha en que se efectuaron las asambleas, y en conformidad con las obligaciones emanadas de dicha Convención, fundamentalmente la de participación política y sobre todo la obligación de consulta, podrían haber sido integradas por personas con discapacidad.

\section{Sistemas de cuotas o asientos reservados para personas con discapacidad en congresos o parlamentos}

Hay poca información disponible sobre cuotas o asientos reservados para personas con discapacidad en los congresos en el mundo. La insuficiencia en la recopilación de datos y estadísticas sobre las personas con discapacidad refleja la falta de priorización que se otorga a esta temática, lo que también alcanza el ámbito de la participación política y pública de estos titulares de derecho. Esta falencia ha sido frecuentemente mencionada por el Comité sobre los Derechos de las Personas con Discapacidad de Naciones Unidas en las observaciones finales hacia los informes de los Estados partes, ${ }^{11}$ como también por el secretario general de Naciones, Unidas que ha enfatizado el lugar central que deben tener las personas con discapacidad en la instauración de políticas públicas, subrayando como pilar la necesidad de una adecuada recopilación de datos y estadísticas sobre este sector de la población. ${ }^{12}$

El estudio temático de Naciones Unidas sobre participación de personas con discapacidad en la vida política y pública indica que Burkina Faso reserva en su legislación nacional cupos para asegurar la adecuada representación de personas con discapacidad en los órganos Legislativo, Ejecutivo y Judicial; sin embargo, no se informó el número de cupos. ${ }^{13} \mathrm{El}$ estudio indica asimismo que el gobierno de México está estudiando una reforma del Código Federal de Instituciones y Procedimientos Electorales para alentar a los partidos políticos a establecer un cupo de personas con discapacidad en las listas para las elecciones.

De acuerdo a otro estudio de la Oficina del Alto Comisionado de Naciones Unidas para los Derechos Humanos, Uganda posee un sistema de asientos reservados establecidos en el artículo 78.1 de su Constitución, que incluye cinco asientos reser-

11. «Observaciones finales sobre el informe inicial de Chile», Comité sobre los Derechos de las Personas con Discapacidad, CRPD/C/CHL/CO/1, 13 de abril de 2016, disponible en https://bit.ly/3y4GVm3.

12. «United Nations comprehensive response to Covid-19: Saving lives, protecting societies, recovering better», Naciones Unidas, disponible en https://bit.ly/3IvYXCt.

13. «Estudio temático...», 12. 
vados para personas con discapacidad representantes del colectivo personas en el Congreso. ${ }^{14}$ Asimismo, cada consejo de aldea, parroquia, subcondado y distrito debe incluir al menos un hombre y una mujer con discapacidad, con lo cual hay 47.000 representantes con discapacidad. ${ }^{15}$

Según la Agencia de la Unión Europea para los Derechos Fundamentales, un estudio de 2014 detalló la cantidad de parlamentarios en situación de discapacidad en Europa: 7 en Croacia, 3 en Polonia, 3 en Reino Unido y 1 en Portugal, pero no precisó sobre la existencia de alguna ley de cuotas o escaños reservados. ${ }^{16}$

En 2021, Reino Unido creó un fondo de acceso a elecciones de personas con discapacidad para abordar los bajos niveles de presencia en la vida pública, en el cual se proporcionan subvenciones individuales a las personas con discapacidad que deseen ser candidatas, con la finalidad de cubrir necesidades de apoyo adicionales que surjan como consecuencia de su discapacidad. El programa se congeló en 2015, y en 2019 se puso en marcha por un año el Fondo EnAble, que entregaba subvenciones para la participación de personas con discapacidad en elecciones locales. Otorgó 42 subvenciones para gastos como intérpretes en lengua de señas, tecnología de asistencia, asistentes personales y pago de taxi. Por su parte, el gobierno escocés ha creado su propio fondo para candidatos con discapacidad a las elecciones parlamentarias. ${ }^{17}$

\section{Representación política de las personas con discapacidad en Chile}

De acuerdo a la segunda Encuesta Nacional de Discapacidad en Chile (Endisc) de 2015, un total de 2.836 .818 personas desde los 2 años en adelante presentan una o más discapacidades, lo que equivale al 16,7\% de la población. Más aún, el 20\% de la población sobre los 18 años se encuentra en situación de discapacidad..$^{18}$ Sin embargo, en conformidad a la evaluación de la situación de la representación política de las personas con discapacidad en Chile en el Congreso Nacional, prácticamente allí no hay participación de personas con discapacidad en calidad de parlamentarios.

\footnotetext{
14. "Guidelines for election of representatives of persons with disability (PWDs) in Parliament», Electoral Commission of the Republic of Uganda, 18 de junio de 2017, disponible en https://bit.ly/3dwrrox.

15. «Uganda's reserved elected seats for persons with disabilities», Zero Project, Disponible en https:// bit.ly/3dua14G.

16. Asamblea General de Naciones Unidas, «Estudio temático preparado por la Oficina del Alto Comisionado de las Naciones Unidas para los Derechos Humanos sobre la participación de las personas con discapacidad en la vida política y pública», 2011, disponible en https://undocs.org/es/A/HRC/19/36.

17. «Atlas of electoral gender quotas», International Institute for Democracy and Electoral Assistance, 2013, disponible en https://www.ipu.org/es/node/433; «The right to political participation for persons with disabilities», Human Rights Indicators, 2014, disponible en https://bit.ly/3DyqoHV.

18. «Estudio Nacional de la Discapacidad», Servicio Nacional de la Discapacidad, 2015, disponible en http://endisc.senadis.cl/\#p=1.
} 
El Congreso Nacional se encuentra compuesto por 198 parlamentarios: 43 senadores y 155 diputados. No se encontró información oficial respecto del número de parlamentarios en situación de discapacidad. De acuerdo a información extraoficial, solo un diputado pertenecería a este colectivo. Es decir, la representación de personas con discapacidad alcanza actualmente al $0,41 \%$.

$\mathrm{Al}$ respecto, en sus Observaciones finales a Chile en 2016, con ocasión del Informe Inicial del país, el Comité sobre los Derechos de las Personas con Discapacidad de Naciones Unidas señaló como preocupación del Comité la falta de participación de las personas con discapacidad en los asuntos políticos como en la adopción de legislación y políticas, por lo que recomendó adoptar un mecanismo vinculante de consulta permanente a personas con discapacidad a través de sus organizaciones, incluyendo a las mujeres, a las niñas y los niños con discapacidad, en la adopción de legislación, políticas y otros asuntos de su relevancia.

Las personas con discapacidad son un sector de la población que cruza transversalmente el tejido social del país, pero que resulta invisible en el ámbito de la participación política, especialmente en cuanto a ser elegidos. Antes de la definición de las listas de constituyentes, el Colectivo Nacional de la Discapacidad (Conadis) declaró que la discapacidad debe ser posicionada como un tema político para el enriquecimiento positivo en la manera de ejercer y comprender los procesos electorales, legislativos y constitucionales. Es una contribución cualitativamente significativa porque su perspectiva aporta a la elaboración de un marco político social inclusivo para todas y todos colaborando así a la solidez de la democracia.

Añadieron que las personas con discapacidad participaron en cabildos y asambleas territoriales, en miras a la nueva constitución, en los que formularon propuestas concretas tanto para su sector como para toda la ciudadanía, por ejemplo, en materia de pensiones. Además, agregaron que si la participación política ha de ser lo más representativa posible de la pluralidad social en tanto «el principio democrático reclama la mayor identidad posible entre gobernantes y gobernados», parece forzoso concluir que el acceso a las instituciones democráticas de un grupo que alcanza al $20 \%$ de la población con derecho a voto debería de ser mucho más representativo en los espacios políticos. ${ }^{19}$

De acuerdo a la perspectiva de representación descriptiva, el Congreso Nacional debiese ser un espejo de la sociedad desde el punto de vista de la estructura sociodemográfica, política, económica y cultural del país. Lo propio debería ocurrir con la Convención Constitucional. Se asume que las instituciones deben precisamente reflejar la diversidad social, lo que enriquece el debate político y la opinión pública.

19. Carta del Colectivo Nacional de la Discapacidad, ingresada a la Comisión de Constitución, Legislación, Justicia y Reglamento» en octubre de 2020. 
Con el objeto de impulsar la inclusión social de Personas con Discapacidad, el Conadis afirmó que los Estados deben crear políticas públicas con el objeto de remover las barreras que enfrentan día a día las personas con discapacidad, a fin de alcanzar una verdadera igualdad de oportunidades, y en el siglo XXI, la igualdad material de hecho o de resultados.

Las organizaciones de personas con discapacidad y sus familias propusieron replantearse la necesidad de tomar medidas efectivas para abordar los múltiples desafíos que enfrentan las personas con discapacidad cuando intentan ejercer sus derechos políticos. Por lo mismo, fue central la demanda por cupos reservados en las listas para la elección de convencionales constituyentes. De no garantizarse una representación acorde con el porcentaje de personas en situación de discapacidad en Chile, se hubiese generado el incumplimiento por parte del Estado de sus compromisos internacionales, lo que podría provocar un cuestionamiento sobre la legitimidad del proceso constituyente por parte de la sociedad civil de y para personas con discapacidad tanto a nivel nacional como internacional.

\section{¿Cómo se resolvió el impasse de la modificación constitucional frente a las argumentaciones de las personas con discapacidad?}

El rápido análisis que se generó en el Senado frente a los argumentos planteados por las personas con discapacidad, con base en los estándares internacionales, determinó que se concretara la iniciativa de inclusión de candidatos y candidatas con discapacidad en las listas conformadas por un partido político o pactos electorales de partidos políticos. Para ello, se consensuó un porcentaje del $5 \%,{ }^{20}$ con el objeto de resguardar y promover la participación de las personas con discapacidad en las elecciones de los convencionales constituyentes para redactar la nueva constitución política. Además, se estableció una drástica sanción en el caso de que los partidos o pactos electorales no cumplieran el requisito, ya que se procedería al rechazo de todas las candidaturas que hubiesen propuesto.

De este modo, se produjo la doble vía de partidos que volcaron su mirada hacia las personas con discapacidad para cumplir con el $5 \%$ y de personas con discapacidad que aspiraban ser constituyentes. El resultado de candidatos y candidatas con discapacidad en las listas por partidos o pactos electores de partidos que cumplieron el requisito del $5 \%$ se detalla en la tabla 1, organizados por distritos, mientras que la tabla 2 muestra los resultados referidos a listas independientes.

20. Ley 22.298, «Modifica Carta Fundamental, para reservar escaños a representantes de los pueblos originarios en la integración del órgano constituyente que se conforme para la creación de una nueva Constitución Política de la República», Boletín 13.129-07, 23 de diciembre de 2020, disponible en http:// bcn.cl/2mwem. 
Tabla 1. Candidatos y candidatas con discapacidad en las listas por partidos o pactos electores de partidos para la Convención Constituyente

\begin{tabular}{|c|c|c|c|c|c|}
\hline Nombre (y distrito) & Agrupación & Lista & $\begin{array}{l}\text { Votos } \\
\text { recibidos }\end{array}$ & $\begin{array}{l}\text { Menor } \\
\text { votación } \\
\end{array}$ & Observaciones \\
\hline Sheila Sánchez Copaja (1) & Independiente & Apruebo Dignidad & 1.816 & 3.251 & \\
\hline Luz Núñez Salazar (2) & $\begin{array}{l}\text { Independiente con cupo } \\
\text { de Renovación Nacional }\end{array}$ & Vamos por Chile & 474 & 6.131 & \\
\hline $\begin{array}{l}\text { Katherine Leyton Álvarez } \\
\text { (3) }\end{array}$ & Independiente & Lista del Apruebo & 1.946 & 3.946 & $\begin{array}{l}\text { No hubo candidato electo de la Lista } \\
\text { del Apruebo. }\end{array}$ \\
\hline $\begin{array}{l}\text { Vianney Sierralta Aracena } \\
(3)\end{array}$ & Independiente & $\begin{array}{l}\text { Movimiento Indepen- } \\
\text { diente de Norte }\end{array}$ & 4.148 & 19.736 & \\
\hline Juan Tagle Domínguez (5) & Evópoli & Vamos por Chile & 1.529 & 8.005 & \\
\hline $\begin{array}{l}\text { Katharina Pavletich } \\
\text { Heisig (5) }\end{array}$ & Comunes & Apruebo Dignidad & 5.733 & 13.393 & \\
\hline Camilo Ortiz Rojas (5) & Independient & $\begin{array}{l}\text { Independientes del } \\
\text { Apruebo Región } \\
\text { Coquimbo }\end{array}$ & 2.967 & 6.141 & $\begin{array}{l}\text { No hubo candidato electo de la lista } \\
\text { Independientes del Apruebo. }\end{array}$ \\
\hline Roberto Parra Vallette (6) & $\begin{array}{l}\text { Independiente con } \\
\text { cupo de Revolución } \\
\text { Democrática }\end{array}$ & Apruebo Dignidad & 1.348 & 11.860 & \\
\hline Javiera Viveros Alegría (6) & Independiente & Apruebo Dignidad & 4.443 & 11.860 & \\
\hline $\begin{array}{l}\text { Manuel Gatica Jorquera } \\
\text { (6) }\end{array}$ & Independiente & Lista del Pueblo. & 3.759 & 6.766 & \\
\hline $\begin{array}{l}\text { Pamela Vivanco Montero } \\
\text { (7) }\end{array}$ & Independiente & Lista del Pueblo & 5.195 & 15.073 & \\
\hline $\begin{array}{l}\text { Francisco Silva Busta- } \\
\text { mante (7) }\end{array}$ & Independiente & por la Lista del Pueblo & 1.958 & 15.073 & \\
\hline $\begin{array}{l}\text { Rodolfo Calderón Hernán- } \\
\text { dez (7) }\end{array}$ & Unión Patriótica & Unión Patriótica & 1.070 & 2.596 & $\begin{array}{l}\text { No hubo candidato electo por el } \\
\text { partido Unión Patriótica por la lista } \\
\text { del mismo partido en este distrito. }\end{array}$ \\
\hline Jaime Troncoso Valdés (8) & Partido Socialista & Lista del Apruebo & 1.727 & 9.621 & \\
\hline Katerine Medel Bueno (8) & $\begin{array}{l}\text { Independiente con cupo } \\
\text { de la Unión Demócrata } \\
\text { Independiente }\end{array}$ & Vamos por Chile & 1.937 & 28.380 & \\
\hline $\begin{array}{l}\text { Duilio De LaPeyra Palma } \\
\text { (9) }\end{array}$ & Evópoli & Vamos por Chile & 1.364 & 11.572 & \\
\hline César Sepúlveda Jara (9) & $\begin{array}{l}\text { Partido de Trabajadores } \\
\text { Revolucionarios }\end{array}$ & $\begin{array}{l}\text { Partido de Trabajado- } \\
\text { res Revolucionarios }\end{array}$ & 918 & 9.589 & $\begin{array}{l}\text { No hubo candidato electo de } \\
\text { la lista Partido de Trabajadores } \\
\text { Revolucionarios. }\end{array}$ \\
\hline Darwin Loreto Johns (10) & $\begin{array}{l}\text { Independiente con cupo } \\
\text { del Partido Liberal }\end{array}$ & Lista del Apruebo & 1.046 & 21.914 & \\
\hline Pablo Selles Ferres (10) & Convergencia Social & Apruebo Dignidad & 4.326 & 3.883 & \\
\hline $\begin{array}{l}\text { Daniel Martínez Barrera } \\
\text { (10) }\end{array}$ & Independiente & Lista del Pueblo & 1.439 & 10.558 & \\
\hline Sonia Ulloa Toro (11) & Lista del Pueblo & Lista del Pueblo & 4.492 & 11.906 & $\begin{array}{l}\text { No hubo candidato electo de la Lista } \\
\text { del Pueblo }\end{array}$ \\
\hline $\begin{array}{l}\text { Christian Muñoz Paredes } \\
\text { (12) }\end{array}$ & Partido Radical & Lista del Apruebo & 1.657 & 2.709 & $\begin{array}{l}\text { No hubo candidato electo por la lista } \\
\text { del apruebo. }\end{array}$ \\
\hline
\end{tabular}




\begin{tabular}{|c|c|c|c|c|c|}
\hline Nombre (y distrito) & Agrupación & Lista & $\begin{array}{l}\text { Votos } \\
\text { recibidos }\end{array}$ & $\begin{array}{l}\text { Menor } \\
\text { votación }\end{array}$ & Observaciones \\
\hline $\begin{array}{l}\text { Diego Infante Schkolnik } \\
\text { (12) }\end{array}$ & Independiente & Lista del Pueblo & 3.170 & 20.979 & \\
\hline $\begin{array}{l}\text { Julio Hernández Prado } \\
\text { (12) }\end{array}$ & $\begin{array}{l}\text { Partido de Trabajadores } \\
\text { Revolucionarios }\end{array}$ & $\begin{array}{l}\text { Partido de Trabajado- } \\
\text { res Revolucionarios }\end{array}$ & 218 & 2.709 & $\begin{array}{l}\text { No hubo candidato electo por el par- } \\
\text { tido Trabajadores Revolucionarios. }\end{array}$ \\
\hline $\begin{array}{l}\text { María Soledad Cisternas } \\
\text { Reyes (12) }\end{array}$ & Independiente & $\begin{array}{l}\text { Independientes por } \\
\text { una Nueva Consti- } \\
\text { tución }\end{array}$ & 12.761 & 2.709 & \\
\hline $\begin{array}{l}\text { Carolina García Berguecio } \\
\text { (13) }\end{array}$ & Evópoli & Vamos por Chile & 2.421 & 11.260 & $\begin{array}{l}\text { No hubo candidato electo de Evópoli } \\
\text { por la lista Vamos por Chile. }\end{array}$ \\
\hline $\begin{array}{l}\text { Matías Poblete Sandoval } \\
\text { (13) }\end{array}$ & Partido Republicano & Vamos por Chile & 3.537 & 11.260 & $\begin{array}{l}\text { No hubo candidato electo del } \\
\text { Partido Republicano por la lista } \\
\text { Vamos por Chile. }\end{array}$ \\
\hline Carlos Poblete Gálvez (14) & Igualdad & Apruebo Dignidad & 3.663 & 29.620 & \\
\hline Mario Quijada Silva (15) & Democracia Cristiana & Lista del Apruebo & 2.031 & 7.236 & \\
\hline $\begin{array}{l}\text { Fabián Rodríguez Rivera } \\
\text { (15) }\end{array}$ & $\begin{array}{l}\text { Partido Comunista de } \\
\text { Chile }\end{array}$ & Apruebo Dignidad & 4.945 & 6.012 & \\
\hline Sebastián Tobar (15) & Independiente & Lista del Pueblo & 3.712 & 17.072 & \\
\hline $\begin{array}{l}\text { Adriana Cancino Meneses } \\
\text { (16) }\end{array}$ & Partido Socialista & Lista del Apruebo & 3.741 & & Candidata electa. \\
\hline $\begin{array}{l}\text { Cristian Martínez Calderón } \\
\text { (16) }\end{array}$ & Partido Unión Patriótica & Unión Patriótica & 1.111 & 3.741 & \\
\hline Rebeca Pavez Mery (19) & $\begin{array}{l}\text { Partido por la Demo- } \\
\text { cracia }\end{array}$ & Lista del Apruebo. & 1.029 & 11.067 & \\
\hline $\begin{array}{l}\text { María Valeria Melgarejo } \\
\text { Toledo (20) }\end{array}$ & Independiente & Lista del Pueblo & 2.386 & 11.507 & \\
\hline Cecilia Morovic Vivar (23) & Independiente & $\begin{array}{l}\text { Independientes por la } \\
\text { Nueva Constitución }\end{array}$ & 1.823 & 5.556 & \\
\hline $\begin{array}{l}\text { Cecilia Kramm Kramm } \\
\text { (25) }\end{array}$ & $\begin{array}{l}\text { Independiente con cupo } \\
\text { de Democracia Cristiana }\end{array}$ & Lista del Apruebo & 2.381 & 5.826 & \\
\hline $\begin{array}{l}\text { Marisol Bañares Zúñiga } \\
\text { (25) }\end{array}$ & Partido Republicano & Vamos por Chile & 2.534 & 19.484 & \\
\hline $\begin{array}{l}\text { Roberto Hurtado Guzmán } \\
\text { (26) }\end{array}$ & Independiente & Lista del Apruebo & 1.226 & 13.824 & \\
\hline $\begin{array}{l}\text { Diego Vallejos Guzmán } \\
\text { (26) }\end{array}$ & Independiente & $\begin{array}{l}\text { Insulares e Indepen- } \\
\text { dientes }\end{array}$ & 7.819 & 10.604 & \\
\hline $\begin{array}{l}\text { Gabriela Casanueva } \\
\text { Méndez ( } 28 \text { ) }\end{array}$ & Renovación Nacional & Vamos por Chile & 327 & 4.197 & \\
\hline
\end{tabular}

1. Votos del candidato electo de su agrupación con menor votación, o del candidato que haya tenido la menor votación en caso de que ningún candidato de la lista haya sido electo. 
Tabla 2. Candidatos y candidatas con discapacidad en las listas independientes

\begin{tabular}{|c|c|c|c|c|c|}
\hline Nombre (y distrito) & Agrupación & Lista & $\begin{array}{l}\text { Votos } \\
\text { recibidos }\end{array}$ & $\begin{array}{c}\text { Menor } \\
\text { votación }\end{array}$ & Observaciones \\
\hline Vianney Sierralta Aracena (3) & Independiente & $\begin{array}{l}\text { Movimiento Indepen- } \\
\text { diente de Norte }\end{array}$ & 4.148 & 19.736 & \\
\hline Manuel Gatica Jorquera (6) & Independiente & Lista del Pueblo & 3.759 & 6.766 & \\
\hline Pamela Vivanco Montero (7) & Independiente & Lista del Pueblo & 5.195 & 15.073 & \\
\hline Francisco Silva Bustamante (7) & Independiente & Lista del Pueblo & 1.958 & 15.073 & \\
\hline Daniel Martínez Barrera (10) & Independiente & Lista del Pueblo & 1.439 & 10.558 & \\
\hline Sonia Ulloa Toro (11) & & Lista del Pueblo & 4.492 & & $\begin{array}{l}\text { No hubo candidato electo } \\
\text { de la lista del Pueblo }\end{array}$ \\
\hline Diego Infante Schkolnik (12) & Independiente & Lista del Pueblo & 3.170 & 20.979 & \\
\hline María Soledad Cisternas Reyes (12) & Independiente & $\begin{array}{l}\text { Independientes por una } \\
\text { Nueva Constitución }\end{array}$ & 12.761 & 2.709 & \\
\hline Sebastián Tobar (15) & Independiente & Lista del Pueblo & 3.712 & 17.072 & \\
\hline Doris Morán Abarca (17) & Independiente & $\begin{array}{l}\text { Independientes por la } \\
\text { Nueva Constitución }\end{array}$ & 871 & 1.199 & \\
\hline Alfonso Yáñez León (17) & Independiente & $\begin{array}{l}\text { Independientes por la } \\
\text { nueva Constitución }\end{array}$ & 2.100 & 1.199 & $\begin{array}{l}\text { No hubo candidato } \\
\text { independiente por la } \\
\text { lista independiente por la } \\
\text { nueva constitución }\end{array}$ \\
\hline $\begin{array}{l}\text { María Valeria Melgarejo Toledo } \\
\text { (20) }\end{array}$ & Independiente & Lista del Pueblo & 2.386 & 11.507 & \\
\hline Cecilia Morovic Vivar (23) & Independiente & $\begin{array}{l}\text { Independientes por la } \\
\text { Nueva Constitución }\end{array}$ & 1.823 & 5.556 & \\
\hline Diego Vallejos Guzmán (26) & Independiente & $\begin{array}{l}\text { Insulares e Indepen- } \\
\text { dientes }\end{array}$ & 7.819 & 10.604 & \\
\hline
\end{tabular}

1. Votos del candidato electo de su agrupación con menor votación, 0 del candidato que haya tenido la menor votación en caso de que ningún candidato de la lista haya sido electo.

Finalmente, de las listas de partidos políticos y pactos electorales de partidos, resultó electa la candidata del Distrito 16 del Partido Socialista en la lista del apruebo, con 3.742 votos. Por otra parte, de las listas independientes, la candidata en el Distrito

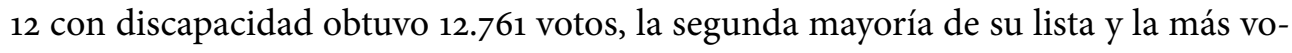
tada del distrito, lo que con la aplicación del sistema D'Hondt hubiera resultado con ella electa como constituyente. No obstante, por la aplicación de la paridad de salida, su cupo fue ocupado por un candidato que obtuvo 2.709 votos, una diferencia fue de 10.052 votos.

Sin duda, este último caso mueve a la reflexión, ya que, si bien se reconoce la virtud de la paridad de género, la Comisión Interamericana de Mujeres (CIM) ha sido clara en señalar que 
es necesario construir Estados incluyentes, democráticos y pluralistas que garanticen los derechos de la ciudadanía, en particular de las mujeres, quienes constituyen más del 50\% de los diversos pueblos de la región, y que han sufrido histórica discriminación [...] por lo que el feminismo plantea la necesidad de adoptar medidas de acción afirmativa y paridad justa entre hombres y mujeres en cargos electivos y mandatos. $^{21}$

Además, la CIM afirma que «el feminismo es un movimiento democratizador, pluralista, diverso y profundamente dialogante que, tanto desde lo individual como desde lo colectivo, incorpora un enfoque interseccional, multirracial, multicultural, multiétnico y multigeneracional, inclusivo y no excluyente». ${ }^{22}$

De lo anterior, es importante subrayar que la paridad justa no debe implicar jamás excluir a mujeres más votadas, ni menos si esta mujer tiene discapacidad, para dejar su cupo a un hombre, sin la aplicación de una medida de acción afirmativa que corrija una situación de discriminación múltiple. Desde luego, esta argumentación puede ser aplicable a otros grupos de mujeres en quienes concurran otra categoría sospechosa de discriminación, lo que debe ser materia de otros estudios, como lo ha sido en este caso el de las mujeres con discapacidad.

La paridad de entrada es una forma de paridad justa, ya que internacionalmente se afirma que las listas deben presentar una configuración de género equitativa de manera alternada y secuencial (uno a uno) en toda su extensión. Ello permite producir entornos igualitarios en la estructuración de la oferta. ${ }^{23}$ En esta dirección, la equidad es el mecanismo a través del cual se configura el diseño de la paridad de género en el armado de las listas partidarias que se oficializan en comicios. ${ }^{24}$

Como se puede apreciar, la paridad de entrada es la que brinda la posibilidad de que mujeres y hombres estén en igualdad de oportunidades para su presentación ante la ciudadanía, la que sin duda es soberana a través del voto. La paridad de salida, entendida como paridad de techo, implica que ningún género puede estar mayormente representado que el otro. En este sentido, la paridad opera como un mecanismo que asegura la igualdad numérica entre hombres y mujeres. ${ }^{25}$ De acuerdo al caso que se

21. «Decálogo para un Estado en clave de derechos humanos y feminista», Comisión Interamamericana de Mujeres, 2021. Disponible en https://bit.ly/3mnC2jf.

22. «La ciudadanía de las mujeres en las democracias de las Américas», Comisión Interamericana de Mujeres, Instituto Internacional para la Democracia y la Asistencia Electoral, IDEA Internacional 2013.

23. «Paridad de género: Política e instituciones», ONU Mujeres, 2021, p. 10, disponible en https://bit. ly/3DBfjpQ.

24. «Paridad de género», 11.

25. Observatorio Constitucional de Género del Centro de Derechos Humanos de la Facultad de Derecho de la Universidad de Chile, «La paridad como piso y sin margen. Hacia un enfoque de género no binario en la nueva Constitución», Facultad de Derecho de la Universidad de Chile, 6 de septiembre de 2021, disponible en https://bit.ly/3ECHwxL. 
ha presentado, este tipo de paridad de salida o de techo aplicada en Chile da claras muestras de la necesidad de corrección a través de medidas de acción afirmativa, de modo que de simple paridad se llegue a una paridad justa, no excluyentes de mujeres más votadas que hombres. La Comisión sobre la Condición Jurídica y Social de la Mujer de Naciones Unidas señala que el enfoque de género busca eliminar las barreras estructurales que impiden la participación de las mujeres y de las niñas, debiendo aplicarse acciones afirmativas y medidas especiales temporales apropiadas, dirigidas a las mujeres, incluidas las que se encuentran en situaciones de vulnerabilidad. ${ }^{26}$

En este sentido, la paridad de salida en su versión de paridad de piso viene a significar la corrección que lleva a la paridad justa. Se entiende por paridad de piso «una medida afirmativa que busca corregir las desigualdades estructurales en la participación de las mujeres. De acuerdo con esto, la paridad asegura una igualdad numérica como un mínimo que puede ser rebasado en favor de ellas». ${ }^{27}$

\section{Conclusiones}

El estándar internacional de la Convención sobre los Derechos de las Personas con Discapacidad de Naciones Unidas, que reconoce el modelo de derechos humanos de las personas con discapacidad, ha sido categórico en promover la participación política de este sector de la población, incluyendo el derecho a presentarse a elecciones políticas y ocupar cargos públicos.

Esta máxima está en concordancia con las obligaciones generales de los Estados partes de la CDPD y los principios del mismo tratado que se refieren a la participación plena y efectiva en la sociedad por las personas con discapacidad en igualdad de condiciones con las demás, lo cual es un factor constitutivo de la conceptualización del titular de derechos.

La eliminación de barreras que enfrentan las personas con discapacidad es una obligación del Estado. Esto se aplica también al ámbito político, con la creación de entornos adecuados para esta forma de participación. Sin embargo, cuando esto no sucede, la mera pasividad por parte del Estado constituye una violación de ese derecho. Así lo ha corroborado la Observación General 7 del Comité CDPD de Naciones Unidas y el Consejo de Derechos Humanos en su estudio temático sobre la participación de las personas con discapacidad en la vida política y pública.

En esta línea, y como forma de asegurar la igualdad y no discriminación de un

26. «Participación de las mujeres y la adopción decisiones por ellas de forma plena y efectiva en la vida pública, así como la eliminación de la violencia, para lograr la igualdad entre los géneros y el empoderamiento de todas las mujeres y las niñas», Consejo Económico y Social de Naciones Unidas, Comisión de la Condición Jurídica y Social de la Mujer, E/CN.6/2021/L.3, 30 de marzo de 2021, p. 15, disponible en https://undocs.org/es/E/CN.6/2021/L.3.

27. «La paridad...». 
sector históricamente infra protegido, la CDPD posibilita la adopción de medidas de acción afirmativas para lograr la igualdad material o de hecho de estos titulares de derechos, lo que es plenamente aplicable al ámbito político.

Lo anterior debe necesariamente conectarse con la obligación de los Estados de adoptar medidas para el desarrollo, adelanto y potenciación de las mujeres con discapacidad, posibilitando el pleno disfrute de sus derechos y eliminando la discriminación múltiple que muchas veces les afecta (artículo 6), lo que también alcanza al ámbito de la participación política. Por ello, ha sido importante el que la paridad de entrada en la experiencia chilena, en algunos casos combinada con los cupos para personas con discapacidad en las listas de partidos y pactos de partidos, haya posibilitado la participación de 19 candidatas con discapacidad. Además, las listas independientes que no tenían la obligación legal del cupo para personas con discapacidad registraron 7 candidatas con discapacidad.

En Chile, según la segunda Encuesta Nacional de Discapacidad en Chile (Endisc) de 2015, un total de 2.836 .818 personas desde los 2 años en adelante presentan una o más discapacidades, lo que equivale al 16,7\% de la población. Por su parte, el 20\% de la población general mayor de 18 años se encuentra en situación de discapacidad. Por ello, las observaciones finales para Chile del Comité CDPD de Naciones Unidas recomendaron la adopción de medidas para facilitar la participación política de las personas con discapacidad.

Frente al proceso de elección de convencionales constituyentes para la elaboración de la nueva constitución política, el proyecto «Modifica la Carta Fundamental, para reservar escaños a representantes de los pueblos originarios en la integración del órgano constituyente que se conforme para la creación de una nueva Constitución Política de la República» contenía incisos finales relativos al 10\% de cupos reservados en las listas de partidos políticos y pactos de partidos para las personas con discapacidad. En la recta final del debate en el Senado, esta propuesta fue eliminada por no estar vinculada a las ideas matrices del proyecto.

No obstante, el movimiento social de personas con discapacidad entregó argumentos a la Comisión de Constitución, Legislación y Justicia del Senado, gracias los actuales hacia las horas finales se logró mantener la propuesta, dejando en $5 \%$ el porcentaje de candidaturas de personas con discapacidad en listas de partidos políticos o listas de pactos electorales de partidos. En caso de que una lista no cumpliera con ese porcentaje, la sanción sería la desestimación de la lista.

De este modo, surgió un proceso rápido de doble vía entre los partidos que buscaban candidatas y candidatos con discapacidad y personas con discapacidad que deseaban contribuir al proceso constituyentes, lo que dio como resultado 30 candidaturas de personas con discapacidad en las listas de partidos políticos o coaliciones de partidos políticos a lo largo de todo el país.

En acápite aparte, debe mencionarse el caso de las listas independientes, las que 
no tuvieron la obligación de incluir a personas con discapacidad. Aun así, hubo candidatas y candidatos con discapacidad participando en estas listas, llegando a un número de 14 postulantes.

Sin duda, los cupos de personas con discapacidad en las listas de partidos y pactos electorales de partidos visibilizaron a este sector de la población, quienes lucharon con fuerza por sus candidaturas. Una candidata con discapacidad del Distrito 16 resultó electa como convencional constituyente, con 3.742 votos.

En el caso de las listas independientes, una mujer con discapacidad del Distrito 12 logró 12.761 votos, lo que le permitía ser electa como constituyente. Sin embargo, la aplicación de la paridad de salida implicó que el cargo fuera ocupado por un candidato varón que había obtenido 2.709 votos, vale decir, 10.052 votos menos. Lo mismo ocurrió con la candidata con discapacidad del Distrito 13, que obtuvo 13.891 votos y que debió ceder su cupo al candidato varón de su lista que obtuvo 11.260 votos, vale decir 2.631 menos.

Basándonos en las elecciones de convencionales constituyentes de 2021, podemos concluir, primero, que en las listas de partidos o pactos de partidos se registraron 30 candidaturas de personas con discapacidad, de las cuales solo una logró ser electa. En el Distrito 13 se perdió una candidata con discapacidad por aplicación del concepto de paridad de salida como techo.

Segundo, en las listas independientes se registraron 14 candidaturas de personas con discapacidad, de las cuales una en el Distrito 12 pudo ser electa, pero quedó atrás por la aplicación de la corrección de paridad de salida, de techo o numérica estricta. Estas dos candidaturas habrían podido proclamarse como electas si se hubiera aplicado la paridad de piso, a la que nos hemos referido con anterioridad.

En consecuencia, el concepto de paridad justa puede identificarse con el concepto de paridad de entrada (lista cebra). En el caso de la paridad de salida, para que esta sea justa, debe ser una paridad de piso. No obstante, si el sistema electoral desea mantener la paridad de techo o numéricamente estricta, debe aplicar una medida de acción afirmativa particular cuando la candidata que peligra ser descartada, aun teniendo más alta votación que los varones, sea una candidata con discapacidad.

Ninguna paridad de salida puede ser justa si excluye a mujeres más votadas y especialmente en situación de discapacidad. Esto amerita una seria reflexión sobre la representación y la aplicación de medidas de acción afirmativa si se desea exhibir una paridad justa, ya que no se puede hacer caso omiso al sustrato de la paridad, que es dar participación y liderazgo efectivo a las mujeres, incluidas aquellas que tienen discapacidad.

No obstante lo expresado, que es una útil reflexión para el debate constitucional en cuanto a la aplicación de los criterios de paridad, es importante no dejar atrás el tema de la participación política de las personas con discapacidad en sentido amplio, esto es incluyendo a mujeres y hombres con discapacidad. Sin duda, los argumentos 
en pro de la participación política de las personas con discapacidad siguen en pie para que sean aplicados en futuras elecciones, por ejemplo, al Congreso Nacional.

La experiencia de la elección de convencionales constituyentes, considerando cupos reservados para las personas con discapacidad en las listas de partidos y pactos de partidos, demostró ser insuficiente para contar con convencionales constituyentes con discapacidad, en directa relación con la proporción de personas con discapacidad de la población chilena, ya que solo una persona con discapacidad resultó electa. Sin embargo, visibilizó a este sector de la población, lo cual es un motivante punto de partida del que no se puede retroceder. Se trata de un camino de toma de conciencia sobre el modelo de derechos humanos de personas con discapacidad en el ámbito de la participación política, que no debe interrumpirse en pos de los derechos humanos de este sector de la población y de la legitimidad democrática. Por lo mismo, la consideración de cupos para personas con discapacidad en las listas para distintas elecciones populares ha sido un buen primer paso y puede considerarse en la nueva Constitución.

De acuerdo con la perspectiva de representación descriptiva, el Congreso Nacional debiese ser un espejo de la sociedad desde el punto de vista de la estructura sociodemográfica, política, económica y cultural del país. En consecuencia, de acuerdo al marco conceptual de esta monografía, y reconociendo que las personas con discapacidad han sido infraprotegidas e invisibles en la sociedad, este estudio considera que una mejora real para dichas personas en términos de representación política sería a través del mecanismo de escaños reservados, propuesta ampliamente sostenida por las personas con discapacidad y que entregan un importante desafío a la Convención Constitucional chilena.

\section{Referencias}

Bisarya, Sumit (2014). Presentación sobre cambios constituyentes: Taller sobre experiencias constitucionales comparadas: Procesos constituyentes y participación ciudadana. Montevideo: Banco Interamericano de Desarrollo

-. (2015). Presentación sobre cambio constitucional. Seminario Internacional: Cambio Constitucional en Democracia. Santiago: Segpres.

\section{Sobre la autora}

María Soledad Cisternas Reyes es abogada y magíster en Ciencias Políticas de la Pontificia Universidad Católica de Chile. Enviada especial de la Secretaría General sobre Discapacidad y Accesibilidad de Naciones Unidas, desde el 2017. Expresidenta del Comité sobre los Derechos de las Personas con Discapacidad de Naciones Unidas (2013-2016). Premio Nacional de Derechos Humanos 2014, Chile. Su correo electrónico es soledad.cisternas@gmail.com. 
